determination of the acylated anthocyanins, pigments from Petunia, Salvia, Raphanus and Matthiola hybrids.

Dr. L. M. Scarpati (University of Rome) discussed in detail the problem of the isomers of chlorogenic acid, showing the caffeoyl ester group to be located at the 5 position of quinic acid in neochlorogenic acid and at the 4 position in 'band 510'. Isochlorogenic acid, a component of coffee beans and for a long time considered to bo an isomer of chlorogenic acid, was revealed as a mixture of three di-O-caffeoyl quinic acids in which the 3,5 isomer predominates.

Dr. D. G. H. Daniels (Cereals Research Station, St. Albans) and Mr. M. O. Naumann (University of Sheffield) in two short communications announced the isolation and characterization of two new types of hydroxycinnamoyl estors, respectively, esters with a long-chain aliphatic (1) diol found in oats and the 2-O-caffeoyl ester of the phenolic glucoside arbutin found in Vaccinium vitis idaea.

The session concluded under the chairmanship of Prof. J. W. Fairbairn and concerned the metabolism of hydroxycinnamic acids in higher plants. Miss J. J. Corner (Low Temperature Research Station, Cambridge) read a paper in which the distribution and formation of the $O$-glucosides and glucose esters of the hydroxycinnamic acids were critically evaluated. Dr. M. H. Zenk (University of Munich) discussed the experimental evidence underlying the important $\mathrm{C}_{6} \mathrm{C}_{3} \rightarrow \mathrm{C}_{6} \mathrm{C}_{1}$ pathway for the formation of plant phenols and proposed a biochemical mechanism for this reaction.
The metabolism of the hydroxycinnamic acids was again considered in the final session on the morning of September 23 when Prof. R. D. Haworth took the chair. Prof. R. A. Thomson (University of Aberdeen) and Prof. $\mathbf{E}$. E. Conn (University of California) discussed the question of the biosynthesis of coumarin from respectively the chemical and biochemical points of view. The pathway of coumarin metabolism was olegantly traced by Prof. Conn, and Prof. Thomson directed attention from a purely chemical point of view to the important stop of ortho-hydroxylation, indicating the possible ways in which this transformation might be achieved.

Prof. W. D. Ollis (University of sheffield) followed with a review of the biogenetic relationships among $\mathrm{C}_{15}$ compounds dorived from cinnamyl precursors; in particular he detailed the possible ways in which the dalbergiones and 4-arylcoumarins might be formed and propounded a theory of oxidative biogenesis to explain the production of the associated benzophenones.

The final paper in the meeting was read by Dr. $M$. Zucker (Agricultural Experimental Station, Connecticut) and concerned an investigation of the biogenesis of chlorogenic acid showing that this is believed to involve a transformation of phenylalanine $\rightarrow$ cinnamic acid $\rightarrow 3-0$ cinnamoylquinic acid $\rightarrow 3-O$-p-coumaroylquinic acid $\rightarrow$ chlorogenic acid.

The meeting was well attended, and the lively formal and informal discussions which followed many of the lectures indicated the interest in phytochemical problems which it is the Group's policy to discuss.

\title{
POP-OUTS ON CONCRETE SURFACES
}

$\mathrm{T}$ HE term 'pop-out' is technically applied to a particular type of disruption or disintegration of concrete surfaces, in serious cases only shortly after casting, with rather special significance. The subject has recently been discussed in a paper by G. M. Idorn (Concrete Research Laboratory, Karlstrup, Denmark) entitled "A Concrete Jetty with Frost Damage" (Magazine of Concrete Research, Coment and Concrete Association, 16, No. 47; 1964).

Mr. Idorn finds that pop-outs on concrete surfaces usually result from exposure to freezing and thawing, involving swelling pressure from ice in certain types of coarse aggregate occurring in Danish gravels. "Pure and silicified limestones and opaline and chalcedonic porous chorts in Danish aggregates are liable to give such pop-outs. These rocks account for about 20-40 per cent in ordinary gravel aggregates (considerably less in the sands).... There is always the possibility that a pop-out has developed because of the swelling pressure from alkali-silica gel in a porous rock particle when it contains or consists of opaline or chalcedonic silica.... The development of alkalisilica gel in a reactive rock particle can also bring about alteration in the interior pore-structure, so that any inherent tendency to be affected by freezing and thawing will increase." This raises again, but in a somewhat different form, the much-debated problem of alkali-reactive aggregate constituents as contributors to disruption of concrete, for example, the mineral chlorophaeite in some dolerites (Nature, 196, 943; 1962).

Whereas chlorophaeite and certain volcanic rock-types as pebbles have been suspect in causing damage to concrete by virtue of their chemical vulnerability and without the assistance of frost, it is now clear that the incidence of frost may considerably enhance the rate at which disruption of the concrete concerned can happen. Pop-outs produce unsightly 'pock-marks', rather like burst blisters, on concrete surfaces where these physico-chemical mechanisms are at work; they lead to extensive scaling. Four general types are recognized by Mr. Idorn: (a) capillary water in porous pebbles freezing to generate pressure on covering mortar; $(b)$ alkali-aggregate reaction in porous cherts, etc., causing fracturing along a 'reaction rim'; (c) in rocks of very low permeability and negligible capillary water, ice may form on the surface of the pebble, destroying the bond, causing covering mortar or laitance to fall off; $(d)$ growth of microscopic ice lenses in the thin layer of mortar or laitance over the pebble, a variation of type $(c)$.

Pop-outs may not, however, fit all cases of surface deterioration of concreto, especially in circumstances where the potential causes of disintegration and exfoliation of mortar, as outlined above, are not in evidence. Mr. Idorn describes his inspection of a jetty in a Baltic harbour where a thick mass-concrete superstructure has suffered severe deterioration due to exfoliation of the mortar, resulting in pools of water where this disruption has occurred. In this case the aggregates used are said to be of excellent quality, "... strong, impermeable and chemically inert, and ... no reason to question the quality of the cement". The concrete had been exposed to severe frost action involving numerous cycles of freozing and thawing during several winters. Of the type of deterioration, he says: "The aggregate pebbles show no sign of disruption themselves, but severo spalling and exfoliation have taken place on the horizontal faces. . . There are many of the exposed coarser-aggregate pobbles forming pop-outs like the types (c) and (d)..." (above). It is emphasized that there is no sign of chemical roactivity in the aggregates used in this concrete, nor is chemical reaction due to sea-water likoly. the salinity of the Baltic being quite low.

These researches and this particular case of the Baltic jetty are revealing, because they clearly demonstrato the mechanical effects of frost attack on concrete surfaces. whethor accelorated by pop-outs or otherwise. The need for further investigations of similar damage, particularly in other countries where this has occurred, is implicit in this most informative essay. 